\title{
"'Why me, why now?" Using clinical immunology and epidemiology to explain who gets nontuberculous mycobacterial infection
}

M. Alexandra Lake ${ }^{1,2}$, Lyn R. Ambrose ${ }^{3}$, Marc C. I. Lipman ${ }^{1,4}$ and David M. Lowe $e^{1,3^{*}}$

\begin{abstract}
Background: The prevalence of nontuberculous mycobacterial (NTM) disease is rising. An understanding of known risk factors for disease sheds light on the immunological and physical barriers to infection, and how and why they may be overcome. This review focuses on human NTM infection, supported by experimental and in vitro data of relevance to the practising clinician who seeks to understand why their patient has NTM infection and how to further investigate.

Discussion: First, the underlying immune response to NTM disease is examined. Important insights regarding NTM disease susceptibility come from nature's own knockouts, the primary immune deficiency disorders. We summarise the current knowledge surrounding interferon-gamma (IFNץ)-interleukin-12 (IL-12) axis abnormalities, followed by a review of phagocytic defects, T cell lymphopenia and rarer genetic conditions known to predispose to NTM disease. We discuss how these define key immune pathways involved in the host response to NTM. latrogenic immunosuppression is also important, and we evaluate the impact of novel biological therapies, as well as bone marrow transplant and chemotherapy for solid organ malignancy, on the epidemiology and presentation of NTM disease, and discuss the host defence dynamics thus revealed. NTM infection and disease in the context of other chronic illnesses including HIV and malnutrition is reviewed. The role of physical barriers to infection is explored. We describe how their compromise through different mechanisms including cystic fibrosis, bronchiectasis and smoking-related lung disease can result in pulmonary NTM colonisation or infection. We also summarise further associations with host factors including body habitus and age.
\end{abstract}

Summary: We use the presented data to develop an over-arching model that describes human host defences against NTM infection, where they may fail, and how this framework can be applied to investigation in routine clinical practice.

Keywords: Nontuberculous mycobacteria, Host defence, Primary immune deficiency, Interferon gamma, Interleukin 12, Bronchiectasis, Cystic fibrosis, Immune response

\footnotetext{
* Correspondence: d.lowe@ucl.ac.uk

${ }^{1}$ Royal Free London NHS Foundation Trust, London, UK

${ }^{3}$ Institute of Immunity and Transplantation, University College London, Royal

Free Campus, Pond Street, London NW3 2QG, UK

Full list of author information is available at the end of the article
}

\section{Biomed Central}

C 2016 Lake et al. Open Access This article is distributed under the terms of the Creative Commons Attribution 4.0 International License (http://creativecommons.org/licenses/by/4.0/), which permits unrestricted use, distribution, and reproduction in any medium, provided you give appropriate credit to the original author(s) and the source, provide a link to the Creative Commons license, and indicate if changes were made. The Creative Commons Public Domain Dedication waiver (http://creativecommons.org/publicdomain/zero/1.0/) applies to the data made available in this article, unless otherwise stated. 


\section{Background}

Nontuberculous mycobacteria have historically been seen as environmental organisms of limited clinical relevance, overshadowed by their more aggressive cousin, Mycobacterium tuberculosis. It was not until the HIV pandemic highlighted disseminated Mycobacterium avium and intracellulare as major opportunistic infection syndromes that their significance was recognised by the general healthcare community, a role further cemented by the expansion of iatrogenic immunosuppression. Evidence to support an ongoing rise in disseminated NTM infection is limited [1]. This is not the case for chronic pulmonary NTM disease which is increasing [2] in part due to an aging, vulnerable population $[3,4]$.

NTM are regarded generally as low pathogenicity organisms, which can be transiently isolated from samples such as sputum, colonise body sites such as the lung, or cause persistent infection and disease. Distinguishing between these different clinical states can be surprisingly difficult. However, it is important to do as this underpins both clinical management decisions and predicts outcome. An accepted approach is to define NTM-associated pulmonary disease as that in which compatible clinical features occur in people from whom NTM are repeatedly isolated over time [5]. Treatment can be poorly tolerated and is certainly less effective than that for tuberculosis (TB) [6]. Hence an understanding of who is at risk enables us to both target interventions and potentially prevent disease occurring.

Research into monogenic disorders conferring susceptibility to disseminated NTM infection provides key insights into the critical host immune responses against these organisms, though many questions remain: in particular why such a large population of apparently immunocompetent people become infected and develop pulmonary disease.

We present here a summary of how specific conditions and iatrogenic interventions have elucidated both the essential and redundant components of human defences against NTM. We use this to suggest practical strategies for investigation in patients presenting with these infections.

\section{Discussion}

\section{Lessons from primary immune deficiencies}

CLINICAL VIGNETTE: A 2-year old boy born to firstcousin parents presents with several weeks of fever, weight loss, diarrhoea and skin nodules. Examination reveals widespread lymphadenopathy and hepatosplenomegaly. Blood cultures are positive for M. avium.

A number of monogenic disorders conferring susceptibility to disseminated NTM infection are grouped together as Mendelian Susceptibility to Mycobacterial Disease (MSMD) conditions. Although extremely rare [7] and predominantly affecting children, these diseases offer insight into critical immune defences against mycobacteria.

\section{Cytokine pathway defects}

The immune response to mycobacterial infection is summarised in Box 1 and Figure 1, together with sites of dysfunction due to primary immunodeficiency syndromes. Essentially, defence is mediated by mononuclear phagocytes' ability to kill mycobacteria and secrete IL-12, augmented by IFN $\gamma$-secreting lymphocytes (especially CD4 ${ }^{+}$T cells).

Increased susceptibility to mycobacterial disease is seen in several human genetic syndromes which result from mutations in critical cytokine pathways affecting IL-12 3 [8, 9], IL-12R $\beta 1$ [10], IFNyR1 [11-13] and IFN $\gamma$ R2 [14]. Mutations in the transcription factor STAT1 [15-19] result in failure to respond to signals from type I (IFN $\alpha / \beta)$, type II (IFN $\gamma$ ) or type III (IFN $\lambda 1$ / $2 / 3$ ) interferons, and bring a dual risk of mycobacterial and viral infections, as can deficiency of tyrosine kinase 2 (TYK2), a janus kinase widely active in cytokine signalling. Loss of mycobacterial infection control in this latter condition is caused by loss of the intracellular signalling cascade triggered by IL-12 and mediated by the interaction of IL-12R $\beta 1$ with TYK2 [20]. Mutations in interferon regulatory factor (IRF)-8 [21] impair production of IL-12 in response to IFN $\gamma$. Mutations in interferonstimulated gene (ISG)-15 [22] also confer susceptibility to NTM: the gene product, interferon-induced $17 \mathrm{kDa}$ protein, is involved in IFNy production by $\mathrm{T}$ and $\mathrm{NK}$ cells. In some of these genetic syndromes, mycobacterial

\section{Box 1. Summary of the key immune responses to mycobacterial infection}

Following internalisation of the mycobacterium, IL-12 is produced by the infected mononuclear phagocyte. This binds to the IL-12 receptor on T or natural killer (NK) cells, which initiates an intracellular signalling cascade culminating in IFNy production. The secreted IFNy then binds to its receptor on the phagocyte to signal via JAK-STAT pathways, resulting in macrophage activation and further $\mathrm{IL}-12$ release, in addition to tumour necrosis factor alpha (TNFa) and interleukin 1 (IL-1). Activated macrophages demonstrate enhanced phagosome maturation, increased killing of intracellular pathogens and upregulated antigen presentation, thereby activating Th1-phenotype T cells to proliferate and release further IFNy. The secreted TNFa plays a critical role in the development of granulomas (reviewed in [112]). 




Fig. 1 The immune response to mycobacterial infection and known sites of dysfunction. Human genetic syndromes which affect the immune response to mycobacterial infection are known to result from disorders in the following genes: ISG15, IL-12B, IL12RB1, IFNGR1, IFNGR2, STAT1, IRF8, ISG-15, GATA2 and NADPH oxidase complex subunit genes such as CYBB. Nontuberculous mycobacteria (A) are phagocytosed (B), triggering release of $\mathrm{IL}-12(\mathrm{C})$, a heterodimeric cytokine formed from the gene products of IL12A and IL12B, which binds a receptor heterodimer (D) of IL-12RB1 and IL-12RB2 on T cells and NK cells. Signalling to the nucleus mediated by TYK2 (E) then results in IFNY production. IFN gamma binds its receptor (F), a heterodimer of IFNGR1 and IFNGR2, triggering phosphorylation of JAK2, JAK1, and STAT1 (G). The resultant phosphorylated STAT1 molecule homodimerises to form the pSTAT1 complex which translocates to the nucleus and binds the IFN gamma activating sequence. This triggers transcription of interferon stimulated genes (ISG) via IRF8 (H), and increases IL12, TNFa, ISG15 (I), and potentiation of macrophage activation. Activated macrophages demonstrate enhanced phagosome maturation and increased killing of intracellular pathogens, and upregulated antigen presentation, thereby activating Th1-phenotype T cells to proliferate and release further IFNץ. TNFa drives development of granulomas. IRF8 aids differentiation of myeloid progenitors into monocytes, and controls transcriptional responses of mature myeloid cells to interferons (IFNS) and Toll-like receptor (TLR) agonists. NFKB is a rapid-acting transcription factor modulated by NEMO (J) and activated by stimuli including signalling through CD40 (K), TLR $(L)$, reactive oxygen species and TNFa. Activation allows a host of inflammatory and immune responses, including IL12 release. Effective intraphagosomal killing through reactive oxygen species requires an intact NADPH oxidase complex (M). Intact haematopoiesis of monocyte lineages is also required via GATA2 (N)

infection has been successfully treated with adjunctive interferon administration [23-26].

Newly described mutations in RAR-related Orphan Receptor C (RORC) predispose to mycobacterial infection as well as mucocutaneous candidiasis. RORC encodes the $R O R \gamma$ and $R O R \gamma T$ isoforms of a transcription factor involved in regulating immune function, cellular differentiation and metabolism. Although susceptibility to candidiasis is due to disturbances in the IL-17 pathway, the increased risk of mycobacterial infection is again via impaired IFN $\gamma$ responses (in this instance from $\gamma \delta \mathrm{T}$ cells and $\mathrm{CCR}^{+} \mathrm{CXCR}^{+} \mathrm{CD} 4^{+} \alpha \beta$ Th1 cells) [27].

Deficiency of nuclear factor- $\kappa \mathrm{B}$ essential modulator (NEMO) results in NTM susceptibility within the diverse phenotype of this $\mathrm{X}$-linked condition, implicating $\mathrm{NF}-\mathrm{kB}$ signalling and by extrapolation the upstream messenger TNF and/or signalling via Toll-like receptors (TLRs) [28, 29].

\section{Phagocyte defects}

Defence against intracellular pathogens such as NTM requires effective intracellular killing by phagocytes including neutrophils, monocytes, macrophages and dendritic cells. In chronic granulomatous disease (CGD), the respiratory burst - critical to phagocyte activation and intracellular killing - is impaired by the lack of functional NADPH oxidase.

A variable proportion of CGD patients (6-57\%, studydependent) develop local and/or systemic complications following vaccination with bacillus Calmette-Guérin (BCG) [30]. The importance of the macrophage respiratory burst in defence against mycobacteria is highlighted by a mutation resulting in a reactive oxygen species 
formation defect in macrophages but not neutrophils that is nevertheless still associated with susceptibility to tuberculosis [31].

Intriguingly, although there is evidence from ex vivo experiments that human neutrophils restrict the growth of or kill many NTM species [32-34] and that neutrophils contribute to the control of $M$. avium in mice [35-37], there is little to suggest that patients with isolated neutrophil disorders or neutropenia have a specifically increased risk of NTM infection.

\section{Other primary immunodeficiency syndromes}

Autosomal dominant deficiency of the transcription factor GATA-2 carries a significant risk of NTM infection [38]. This disorder has a diverse presentation, such that it may be diagnosed at any time from early infancy to old age. Manifestations can vary from the asymptomatic to near-lethal. Typical features include monocytopenia, $B$ and NK cell cytopenias, and myelodysplastic syndrome. Although multiple factors may contribute to NTM susceptibility, including NK cell deficiency and impaired cytokine release [39], the simplest explanation is a deficiency of mononuclear phagocytes [40, 41].

Immunodeficiencies that profoundly affect the number or function of T cells also predispose to NTM infection (as well as many other pathogens). This includes Severe Combined Immune Deficiency (SCID) [42] but also isolated $\mathrm{CD}^{+}{ }^{+} \mathrm{T}$ cell deficiency [43], which is associated with both pulmonary and disseminated infection, emphasising the importance of this T cell type.

Some primary immunodeficiencies are not associated with a significantly increased risk, including the antibody-deficiency syndromes, such as Common Variable Immunodeficiency (CVID) [44] and X-linked Agammaglobulinaemia (XLA) [45]. The occasional NTM infections which do occur in such patients are generally associated with significant bronchiectasis - itself an independent risk factor, as described later.

\section{Interferon- $\gamma$ autoantibodies}

Another characterised immune defect affecting host defence against NTM is anti-IFN $\gamma$ autoantibody formation $[46,47]$. A cohort of NTM patients, frequently of Asian origin and over 60 years old, have been demonstrated to produce these antibodies [48-50]. Analysis typically demonstrates loss of IFN $\gamma$-mediated augmentation of TNF $\alpha$ and STAT1 phosphorylation in whole blood, which normalises when serum is removed, consistent with the presence of inhibitory antibodies against IFNY [50]. Notably, patients with treatmentrefractory disseminated NTM infection and IFNY autoantibodies have been successfully treated with anti-CD20 (Rituximab) and experienced sustained remission from infection $[51,52]$.
Autoantibodies against IL-12 are also described, especially in association with thymoma [53]. These may be expected to increase risk of NTM infection, though their clinical significance remains unclear at present. Importantly, autoantibodies including those directed against cytokines, tend to be more prevalent in older adults [54].

\section{Immunological insights from NTM patients and genome-wide associations}

Many of the disorders discussed so far represent fundamental defects in key antimycobacterial pathways, and often manifest as disseminated infection in young people. However, older patients with isolated pulmonary NTM (p-NTM) infection may have more subtle abnormalities of the same immunological processes, such as impaired IFN $\gamma$ (and often TNF $\alpha$ ) production [55-57] in stimulated whole blood or peripheral blood mononuclear cells. There are also reports of clinical improvement with the administration of IFNy in patients with pulmonary MAC infections [24, 58].

However, these findings are not consistently replicated: in a prospective cohort study of 63 adults with p-NTM, no significant abnormality of immune function was found in the IL-12/IFN $\gamma$ axis or numbers of lymphocyte subsets [59]. Studies of other cytokines in NTM disease including TGF- $\beta$, IL10, IL-17, and IL-18 reveal a differential balance relative to controls $[60,61]$. This may indicate that multiple subtle immunological abnormalities co-exist in some patients that together increase overall risk. In another example of this, a recent report found an increased frequency of potentially significant polymorphisms in immune system genes (including IRF8 and STAT1) among NTM patients compared with their relatives or healthy controls [62]. One gene where polymorphisms are enhanced in NTM is NRAMP1, whose product improves resistance to intracellular pathogens by decreasing intraphagosomal iron and increasing production of inducible nitric oxide synthase (iNOS) [63]. Deleterious mutations in such a pathway would be consistent with the core immunological defence against mycobacteria: that is, a requirement for functional mononuclear phagocytes (especially macrophages) to kill mycobacteria, functional $\mathrm{CD} 4^{+} \mathrm{T}$ cells plus intact production of, and response to, IFN $\gamma$, IL-12 and TNF $\alpha$.

Beyond intrinsic defects in host immunity, there are several other risks for NTM infection. These are summarised in the following sections.

\section{Systemic illness}

CLINICAL VIGNETTE: A 35-year old patient with significant graft-versus-host disease, eight weeks after unrelated-donor stem cell transplant for acute myeloid leukaemia, presents with fevers and malaise. Blood 
cultures from an indwelling central venous catheter are positive for M.fortuitum.

A number of systemic illnesses increase the likelihood of NTM infection. This association can generally be understood in terms of the key immune responses describe above. For example, there is a clear and longestablished relationship between disseminated NTM infection (especially M.avium/intracellulare) and HIV-1seropositivity, with the risk increasing sharply when the $\mathrm{CD}^{+}{ }^{+} \mathrm{T}$ cell count falls below $50 / \mathrm{mm}^{3}$ [64]. There is also an increased risk of isolated pulmonary disease, especially with M.kansasii [65], whose pathogenicity and clinical manifestations more closely resemble tuberculosis than other NTMs. Again, the $\mathrm{CD} 4^{+} \mathrm{T}$ cell count is usually low [66].

Recipients of solid organ transplants are particularly vulnerable to NTM, consistent with their broad diseaserelated and iatrogenic immunosuppression [67-70]. Similarly, stem cell transplant recipients, who have a profound deficiency of all lymphoid and myeloid cell types, are at significantly increased risk of NTM infection. This includes rapid-growing species which can cause central catheter infections [71]. Notably, the majority of infections probably occur outside periods of neutropenia [72], again confirming relative redundancy of neutrophils in NTM defence.

Other diseases, for example rheumatoid arthritis, are associated with heightened risk of NTM. This may relate to intrinsic T cell dysfunction [73] but also to the use of immunosuppressive medications, associated lung disease or reduced leptin levels - all discussed below. Diabetes, which is an established risk factor for TB [74] has, curiously, not been implicated in NTM infection to date.

\section{latrogenic immunosuppression \\ Targeted therapies}

As described, TNF $\alpha$ is essential for granuloma formation. Correspondingly, there is a significant risk of developing either pulmonary or disseminated NTM infection with anti-TNF $\alpha$ treatment [75]. An analysis of the United States Food and Drugs Administration database of adverse events associated with TNF $\alpha$ inhibitors revealed over 100 confirmed and probable cases of NTM infection in that population. The most common organism was Mycobacterium avium, and $44 \%$ of cases demonstrated extrapulmonary disease [76].

Other biologic and newer small molecule synthetic therapies are less well studied, but theoretical risks based on their impact versus the key NTM defences detailed above - are discussed in Box 2 and Table 1 . Those agents with high associated risk $(++$ or +++$)$ are more likely to predispose to disseminated NTM disease than those with modest or low risk, although concomitant immunocompromise from underlying conditions or adjunctive treatments would compound the effect of any agent. All implicated therapies may predispose to pulmonary infection, especially in patients with structural lung disorders. Current best practice for clinicians considering prescribing biologic immunosuppressive agents is to carry out a screen for latent $\mathrm{TB}$ prior to initiating therapy. We suggest that consideration should also be given to detecting NTM infection (via sputum culture) prior to treatment with high-risk molecules, especially in patients with underlying pulmonary disease.

\section{Broadly acting immunosuppressive agents}

Within the adult NTM disease patient population there is a considerable burden of chronic respiratory disease (discussed below). Inhaled and oral steroids are frequently used for treatment of many of these conditions, and a corresponding increased susceptibility to disease is found. In a Danish population-based study of respiratory disease, use of inhaled corticosteroids in COPD increased the odds ratio for p-NTM disease from 7.6 to 19.6, and a dose-risk response was noted with increasing doses [77]. A relationship with steroids and rising NTM disease risk is also seen in the treatment of rheumatoid arthritis [78] and asthma [79].

NTM disease has been associated with immunosuppressive medications such as azathioprine, cyclophosphamide, mycophenolate and cyclosporine, as well as with anti-TNF $\alpha$ agents [78]. Again, clinicians should consider screening for NTM before starting these drugs and remain vigilant for infection and disease during treatment.

\section{Structural lung disease}

CLINICAL VIGNETTE: A 76 male smoker with known COPD was investigated for new changes on his chest radiograph associated with increased sputum and a gradual reduction in his exercise capacity. He had not responded to several short courses of antibacterials. Sputum cultures isolated $M$. xenopi with no initial evidence for underlying lung neoplasia.

Discussion thus far has focussed on immunological defences against NTM infection, but it is clear that the physical barriers integral to healthy lungs are also critical. In p-NTM disease case series, chronic respiratory diseases such as bronchiectasis and COPD are common associations. Equally, NTM prevalence in bronchiectasis is high [80] - estimated at $9.3 \%$ according to a recent meta-analysis [81]. Given that lung damage, such as cavitation or bronchiectasis, is often regarded as an integral component of p-NTM disease diagnosis [5], it can be difficult to determine whether lung structural changes predispose to, or 


\section{Box 2. Risk for NTM infection from monoclonal antibodies and small molecule medications}

Anti-cytokine/cytokine signalling medications

Of significant theoretical concern is the IL-12/23 inhibitor ustekinumab, given the central role of this cytokine in combating mycobacteria; a report has been published of TB reactivation [113], but further data are required. The JAK pathway inhibitors tofacitinib and ruxolitinib interfere with interferon signalling (as described earlier) and should also therefore carry a significant risk. Tofacitinib appears to carry a similar risk of TB to anti-TNF agents [114] and disseminated TB on ruxolitinib is described [115]. Data are currently scarce on these agents, but the immunological basis of risk for NTM infection is clear.

B cell targeted therapies

Although cases of NTM infection have been associated with the anti-CD20 monoclonal rituximab, reports remain rare and are usually in patients receiving other immunosuppressives [116], while the risk of TB is not significantly increased [114]. This is consistent with a relatively minor role for $\mathrm{B}$ cells and antibodies in host defence against mycobacteria. However, clinicians should be aware that hypogammaglobulinemia secondary to B cell-targeted therapies will increase risk of bronchiectasis and thereby colonisation or infection with NTM.

Anti-inflammatory agents

The anti-IL-6 agent tocilizumab and CTLA-4 agonist abatacept (which reduces co-stimulation from antigen-presenting cells to T cells) both impair Th1 responses and might be expected to modestly increase risk of mycobacterial infection. Preliminary data may support some risk of NTM, at least for tocilizumab [116, 117]; correspondingly, the incidence of TB is increased modestly with both agents but not to the level seen with TNFa blockade [114]. Molecules which interfere with the IL-1 axis (anakinra and rilonacept) similarly interrupt inflammatory responses and may modestly increase risk of NTM infection. The a4-integrin component is expressed on many leucocytes including lymphocytes and mononuclear phagocytes: the inhibitor natalizumab interferes with their migration and might increase risk of infection - as has been reported [118].

Drugs used in malignancies and organ transplantation

It is probably less useful to consider specific risks of agents used for malignancies and in organ transplant due to the profoundly immunosuppressive effects of the underlying conditions and adjunctive treatments. Nevertheless, molecules acting against $T$ cell and/or mononuclear phagocyte receptors such as CD25/IL-2R (eg daclizumab, basiliximab), CD3 (muromonab) or CD52 (alemtuzumab)

would all be expected to increase the risk, whereas those targeting growth factors or tissue-specific antigens would not.

Others

Denosumab inhibits RANKL, expressed on T helper cells and involved in differentiation of some mononuclear phagocytes, and thus may be expected to increase risk although there is no supporting data so far. This is important to establish as the population more likely to have osteoporosis (elderly women) are also at increased risk of NTM infection. In contrast, some agents target elements of the immune system not involved in defences against NTM, such as omalizumab (anti-lgE) or eculizumab (anti-complement component C5) and should not be associated with NTM infection.

arise as a consequence of, p-NTM disease. Although non-CF bronchiectasis is a diverse entity with multiple aetiologies, a unifying patho-mechanism is provided by Cole's vicious cycle model [82] where local pulmonary damage results in non-clearing infection that leads to an excessive inflammatory response, with consequent further lung damage (dilatation and destruction, i.e. bronchiectasis) and more infection.

The complexity of predisposition to p-NTM disease is demonstrated by a whole-exome sequencing study of 69 immunocompetent p-NTM disease patients and 18 unaffected family members. This revealed that patients with p-NTM have more low-frequency, protein-affecting variants in immune, cystic fibrosis transmembrane conductance regulator (CFTR), cilia, and connective tissue genes than their unaffected family members and control subjects [62], demonstrating the complexity of predisposition to NTM disease.

\section{Chronic obstructive pulmonary disease}

COPD is a chronic, progressive lung disease characterised by airflow limitation with poor reversibility. Lung injury, triggered most often by smoking, causes inflammation, tissue destruction and remodelling of elastin and collagen, with occlusion of small airways by narrowing, obliteration and mucus plugs [83], The heightened susceptibility to infection was demonstrated in a prospective cohort of COPD exacerbations where $22 \%$ of subjects were culture-positive for NTM [84]. The extent to which NTM infection itself 
Table 1 Potential effects of targeted small molecule/monoclonal agents on risk of NTM Infection

\begin{tabular}{|c|c|c|c|c|c|c|}
\hline \multirow{2}{*}{ Target } & \multirow[b]{2}{*}{ Example(s) } & \multicolumn{4}{|c|}{ Element of NTM immune response targeted? } & \multirow[b]{2}{*}{ Theoretical risk for NTM † } \\
\hline & & T cells & Mononuclear phagocytes & Key cytokines & Other Th1 cytokines & \\
\hline TNF & $\begin{array}{l}\text { Infliximab } \\
\text { Certolizumab } \\
\text { Adalimumab } \\
\text { Etanercept } \\
\text { Golimumab }\end{array}$ & $\mathrm{N}$ & $\mathrm{N}$ & Y & $\mathrm{N}$ & +++ \\
\hline IL-12/23 & Ustekinumab & $\mathrm{N}$ & N & Y & N & +++ \\
\hline JAK & $\begin{array}{l}\text { Ruxolitinib } \\
\text { Tofacitinib }\end{array}$ & $?$ & Y & Y & N & +++ \\
\hline CD52 & Alemtuzumab & Y & Y & N & $?$ & ++ \\
\hline CD25/IL2R & $\begin{array}{l}\text { Basiliximab } \\
\text { Daclizumab }\end{array}$ & Y & $?$ & N & $?$ & ++ \\
\hline CD3 & Muromonab & Y & N & $\mathrm{N}$ & N & ++ \\
\hline a4-integrin component & Natalizumab & Y & Y & N & N & ++ \\
\hline IL-6R & Tocilizumab & $N$ & N & N & Y & + \\
\hline CTLA-4 (agonist) & $\begin{array}{l}\text { Abatacept } \\
\text { Belatacept }\end{array}$ & $\mathrm{N}$ & Y & $?$ & Y & + \\
\hline IL-1R1/IL-1 $\beta$ & $\begin{array}{l}\text { Anakinra } \\
\text { Rilonacept }\end{array}$ & N & N & $N$ & Y & + \\
\hline CD30 & Brentuximab & Y & N & N & N & \pm \\
\hline RANKL & Denosumab & Y & Y & N & N & \pm \\
\hline CD20 & $\begin{array}{l}\text { Rituximab * } \\
\text { Ofatumumab * }\end{array}$ & $\mathrm{N}$ & N & N & N & - \\
\hline BLyS/BAFF & Belimumab * & $N$ & $?$ & N & N & - \\
\hline Btk & Ibrutinib * & $\mathrm{N}$ & $?$ & $\mathrm{~N}$ & N & - \\
\hline HER-2/erbB & $\begin{array}{l}\text { Trastuzumab } \\
\text { Pertuzumab } \\
\text { Erlotinib }\end{array}$ & N & N & N & N & - \\
\hline VEGF/VEGFR & $\begin{array}{l}\text { Bevacizumab } \\
\text { Ranibizumab } \\
\text { Aflibercept } \\
\text { Axitinib } \\
\text { Lapatinib }\end{array}$ & N & N & N & N & - \\
\hline EGFR & $\begin{array}{l}\text { Panitumumab } \\
\text { Afatinib } \\
\text { Gefitinib }\end{array}$ & $N$ & N & N & $\mathrm{N}$ & - \\
\hline BcrAbl & $\begin{array}{l}\text { Bosutinib } \\
\text { Nilotinib }\end{array}$ & N & N & N & N & - \\
\hline C5 & Eculizumab & $\mathrm{N}$ & N & N & N & - \\
\hline $\lg E$ & Omalizumab & $N$ & N & N & $N$ & - \\
\hline GPIIb/IIla & Abciximab & $N$ & $\mathrm{~N}$ & $\mathrm{~N}$ & $\mathrm{~N}$ & - \\
\hline
\end{tabular}

* Target B cells - note risk of hypogammaglobulinemia and secondary bronchiectasis

†+++ very significant risk, ++ significant risk, + some risk, \pm unclear risk, - no risk

$\mathrm{Y}=$ Yes, $\mathrm{N}=\mathrm{No}, ?=$ possible

TNF, tumour necrosis factor; IL, interleukin; JAK, Janus activated kinase; CD, cluster of differentiation; CTLA-4, cytotoxic T-lymphocyte-associated protein 4; RANKL, Receptor activator of nuclear factor kappa-B ligand; BLyS, B lymphocyte stimulator; BAFF, B cell activating factor; Btk, Bruton's tyrosine kinase; HER-2, Human epidermal growth factor receptor 2; $\operatorname{VEGF}(\mathrm{R})$, vascular endothelial growth factor (receptor); EGFR, epidermal growth factor receptor; C5, complement component C5; IgE, Immunoglobulin E; GPIIb/Illa, Glycoprotein Ilb/llla; NTM, nontuberculous mycobacteria; Th1, T helper 1

may promote COPD has been investigated, and might partly explain the apparent high frequency of reported mycobacterial isolation [85]. Both bronchiectasis and COPD are characterised by neutrophilic inflammation
[86, 87]. As described previously, this cell type is probably not central to NTM defence, but instead can cause host damage via the release of cytotoxic contents and thereby further compromise physical barriers to infection. 


\section{Cystic fibrosis}

Specific mutations in the CFTR gene, most commonly the delta-F508 mutation, lead to defective function of the cyclic-AMP stimulated chloride channel in the membrane of epithelial cells and the clinical disease of cystic fibrosis (CF). Homozygosity for these mutations results in disordered sodium and chloride transport across the epithelium with thickened respiratory secretions. The heightened risk of pulmonary infection is well established, and has a complex aetiology ranging from impaired mucociliary function and viscous, inspissated secretions, to compromise of many immunological defences [88].

The predisposition to NTM infection is striking: CF respiratory cultures exhibit a 10,000 fold greater prevalence of NTM than the general population, with the most common being Mycobacterium avium complex (MAC) and M. abscessus [89]. The importance of studying this population is highlighted by the reported transmissibility of $M$. abscessus from patient to patient [90]. The implication of this for people at high risk of NTM disease using healthcare services with other NTM patients is considerable. Importantly, there are an increasing number of reported CFTR polymorphisms that do not result in frank CF but nonetheless may predispose to bronchiectasis and NTM infection [62, 91-93].

Other associations with structural lung disease are summarised in Box 3. In all of these cases, it remains difficult to determine how much of the NTM colonisation, infection and disease relate to anatomical changes and secretions that are hard to clear, and how much to associated dysregulated immune and inflammatory responses.

\section{Other host traits as risk factors for NTM infection}

Aging appears to increase susceptibility to p-NTM disease (the mean age at presentation in a US study was 68.2 years [94]). Age greater than 65 is also associated with worse outcomes (hazard ratio for death 9.17, $95 \%$ confidence interval 4.98-16.86 [95]). Whilst this may simply reflect the fact that predisposing factors for NTM infection, such as structural lung disease, are more

\begin{tabular}{l} 
Box 3. Structural lung diseases associated with \\
pulmonary NTM \\
\hline Alpha-1 antitrypsin [119] \\
COPD \\
Cystic Fibrosis \\
Non-CF Bronchiectasis \\
Pneumoconiosis [77, 120, 121] \\
Pulmonary alveolar proteinosis [122]
\end{tabular}

common with age, immunosenescence [96-99] affecting key host defences (especially $\mathrm{T}$ cell function) may also be important.

Many p-NTM prevalence studies reveal a greater number of female than male patients [2, 59, 100]; females with non-CF bronchiectasis seem to be at particularly high risk [80]. A possible explanation may be the lower levels of oestrogen in post-menopausal females, as experiments in ovariectomised mice show that oestrogen enhances the clearance of MAC [101], albeit human data are inconclusive [102, 103].

Low body mass index (BMI) appears to be a risk factor for NTM infection, with a protective effect seen at higher BMIs [55, 104, 105]. Lower levels of subcutaneous fat are present in p-NTM patients compared to controls [106]. It has been suggested that the adipokines leptin and adiponectin may be responsible. Leptin, a hormone expressed by white fat cells and whose levels positively correlate with body fat, regulates satiety but also has immunomodulatory effects such as driving $\mathrm{T}$ cell differentiation towards a Th1 IFN $\gamma$-producing phenotype, enhancing phagocyte function and increasing TNF and IL-12 secretion [55]. Leptin deficient mice $(o b / o b)$ mice have delayed clearance of Mycobacterium abscessus lung infection compared to wild-type mice [107]. Conversely, adiponectin is a protein that has a role in fatty acid oxidation and inversely correlates with body fat; this adipokine has immunosuppressive effects on Th1 responses [104].

P-NTM disease has been reported in a patient group characterised by greater than average height, thoracic skeletal abnormalities and mitral valve prolapse [59]. The evidence that this is related to an underlying connective tissue disorder is currently limited [108]. However, abnormalities of the thoracic skeleton such as scoliosis and pectus excavatum do appear to be more common than in patients with $\mathrm{TB}$ or the general population $[105,109]$.

Severe vitamin D deficiency appears to be associated with p-NTM disease [110], although the mechanism remains less clear than for M.tuberculosis [111].

\section{Summary}

NTM are increasingly isolated from respiratory secretions, and this appears to reflect a rise in true disease. Analysis of immune function and host phenotype reveals the fundamental mechanisms of successful host defence against NTM. These are an intact IFN $\gamma$-IL-12 axis, effective phagocytosis and intracellular killing, adequate monocyte haemopoiesis and circulating $\mathrm{CD}^{+} \mathrm{T}$ cell numbers, plus an undamaged pulmonary epithelium with effective clearance of secretions. Most NTM lung disease occurs in older patients. At our current level of knowledge, the largest patient population, i.e. people 

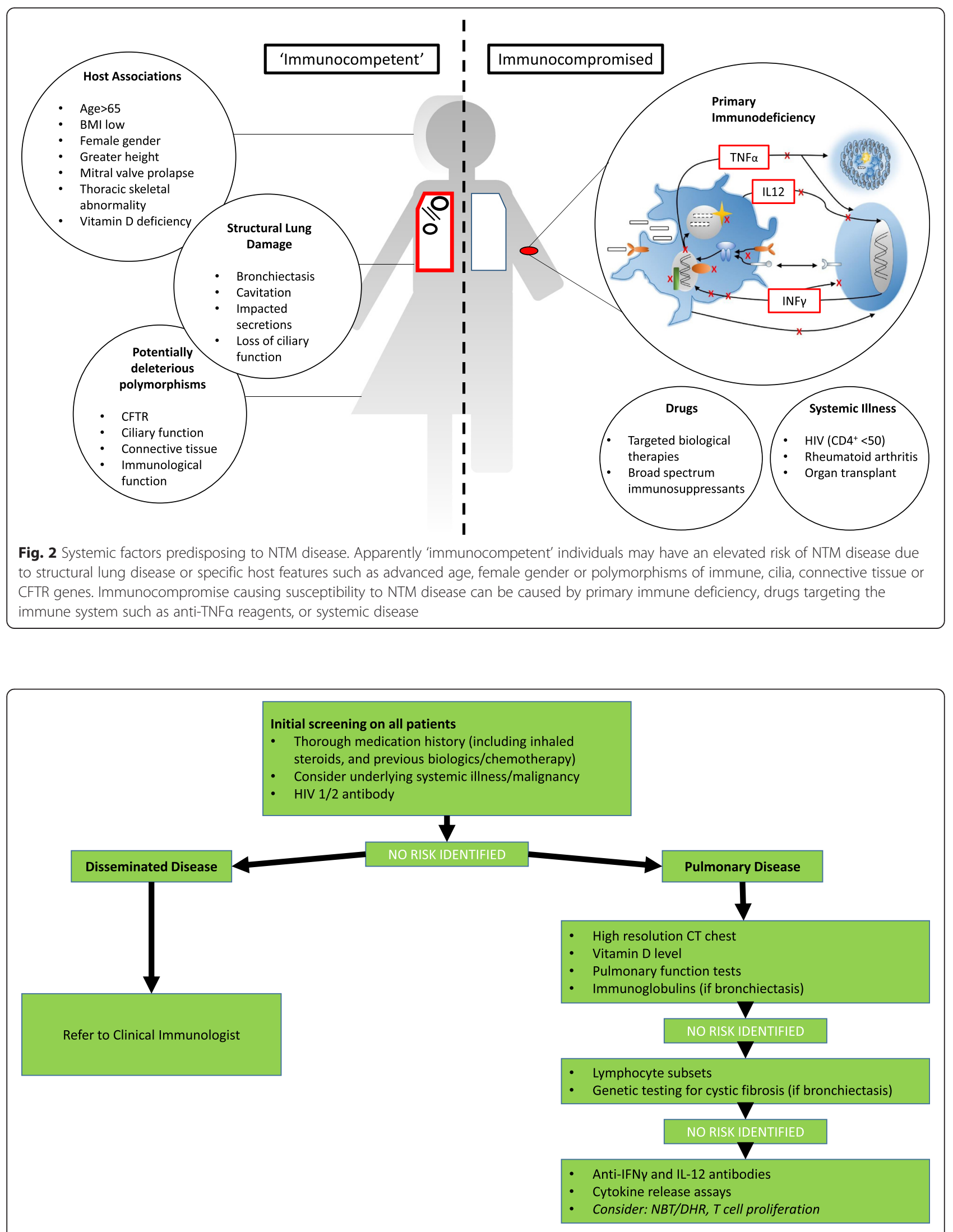

Fig. 3 Flowchart for investigation of adult patients presenting with NTM disease 
with isolated lung disease, appear to have minimal evidence for clear-cut, underlying immune defects. However, a small but important group will have demonstrable and relevant alterations in their ability to control NTM infection. Furthermore, subtle immune perturbations may combine with lung damage to increase the overall risk of NTM infection and disease.

Figure 2 summarises the elements described in this article. Many of these risks are predictable and modifiable: clinicians and patients alike should strive to avoid NTM infection as its treatment is prolonged and associated with considerable morbidity [5].

The degree to which investigations are performed to identify these risks depends on the patient's clinical features and resources available. Figure 3 lists our advice for the investigation of adult patients presenting with NTM infection. Children or anyone presenting with apparently unexplained disseminated infection should be referred to a clinical immunologist and undergo whole exome sequencing if no defined susceptibility is identified; the pathway for investigating early-onset MSMD conditions has been described elsewhere [69].

All adult patients should be offered HIV testing and assessed for underlying disease leading to immune compromise. A careful drug history should include biologics or other therapies whose most recent administration may have been weeks or months previously. Vitamin D deficency is an easily reversible risk factor.

Clinicians should be aware in particular of the haematological characteristics of GATA-2 deficiency (monocytopenia, NK and B cell cytopenias), due to its protean manifestations and wide range of age at first presentation. Lymphocyte subsets help to identify this pattern as well as idiopathic CD4 lymphopenia.

In pulmonary infection, the wide availability of high resolution CT lung scanning at an acceptable radiation dosage means that this is now an important component of p-NTM work-up. Lung function tests will help to identify COPD in patients without a pre-existing diagnosis, and also serve as a baseline for future management. We advocate testing immunoglobulins in patients with bronchiectasis to exclude an immunological basis for the structural lung disease, even though hypogammaglobulinemia is not a particular risk for NTM infection itself. Patients with significant bronchiectasis should be investigated for underlying $\mathrm{CF}$.

If no abnormalities are identified via these tests then we advocate assessing for response to, and release of, IFNY and IL-12. Defects in these pathways can present clinically at a later age, and the tests can inform whether IFN $\gamma$ may be a treatment adjunct worth considering. Anti-cytokine antibodies are more common in older patients and should be measured; if present, consideration may be given to immunomodulatory therapy (i.e. rituximab). $\mathrm{T}$ cell proliferation and assays for CGD should be considered if there is a compatible history, especially of other opportunistic infections.

\section{Abbreviations \\ BCG: bacillus Calmette-Guérin; CGD: chronic granulomatous disease; CFTR: cystic fibrosis transmembrane conductance regulator; \\ CVID: Common Variable Immunodeficiency; DHR: dihydrorhodamine; HIV: human immunodeficiency virus; IFNY: interferon gamma; L: interleukin; MAC: Mycobacterium avium complex; NBT: nitroblue-tetrazolium; NEMO: nuclear factor-KB essential modulator; NK cells: natural killer cells; NTM: nontuberculous mycobacteria; PID: primary immune deficiency; p-NTM: pulmonary nontuberculous mycobacteria; RORC: RAR-related Orphan Receptor C; SCID: Severe Combined Immune Deficiency; TB: tuberculosis; TNFa: tumour necrosis factor alpha; XLA: X-linked Agammaglobulinaemia.}

\section{Competing interests}

The authors declare that they have no competing interests.

\section{Authors' contributions}

All authors have given final approval of the version to be published and agree to be accountable for all aspects of the work in ensuring that questions related to the accuracy or integrity of any part of the work are appropriately investigated and resolved. MAL drafted the main body of the manuscript. LA reviewed and summarised primary laboratory studies. MCL participated in the review design and helped draft the manuscript. DL conceived of the review, participated in its design and helped draft the manuscript. All authors read and approved the final manuscript.

\section{Authors' information}

$M C L$ is a respiratory physician and $D L$ is an immunologist and infectious diseases physician at the Royal Free Hospital, London, UK. MAL is an honorary research associate and specialist registrar in infectious diseases, and LA is a research scientist. The hospital is a tertiary referral centre for immunodeficiency and infectious disease, has a large transplant service and has a significant patient population with isolated pulmonary NTM infection. MCL and DL have an active research programme in tuberculosis which is now increasingly focussing on non-tuberculous mycobacteria.

\section{Author details}

${ }^{1}$ Royal Free London NHS Foundation Trust, London, UK. ²Division of Infection and Immunity, University College London, London, UK. ${ }^{3}$ Institute of Immunity and Transplantation, University College London, Royal Free Campus, Pond Street, London NW3 2QG, UK. ${ }^{4}$ UCL Respiratory, Division of Medicine, Faculty of Medical Sciences, University College London, Royal Free Campus, London, UK.

Received: 19 December 2015 Accepted: 18 March 2016

Published online: 23 March 2016

\section{References}

1. Chetchotisakd P, Kiertiburanakul S, Mootsikapun P, Assanasen S, Chaiwarith R, Anunnatsiri S. Disseminated nontuberculous mycobacterial infection in patients who are not infected with HIV in Thailand. Clin Infect Dis. 2007:45:421-7.

2. Prevots DR, Shaw PA, Strickland D, Jackson LA, Raebel MA, Blosky MA, et al. Nontuberculous mycobacterial lung disease prevalence at four integrated health care delivery systems. Am J Respir Crit Care Med. 2010;182:970-6.

3. Adjemian J, Olivier KN, Seitz AE, Holland SM, Prevots DR. Prevalence of nontuberculous mycobacterial lung disease in U.S. Medicare beneficiaries. Am J Respir Crit Care Med. 2012;185:881-6.

4. Shah N, Davidson J, Anderson L, Lalor M, Kim J, Thomas H, et al. BMC Infectious Diseases Pulmonary Mycobacterium avium-intracellulare is the main driver of the rise in non-tuberculous mycobacteria incidence in England, Wales and Northern Ireland, 2007-2012. BMC Infect Dis. 2016. In Press.

5. Griffith DE, Aksamit T, Brown-Elliott BA, Catanzaro A, Daley C, Gordin F, et al. An official ATS/IDSA statement: diagnosis, treatment, and prevention of 
nontuberculous mycobacterial diseases. Am J Respir Crit Care Med. 2007;175:367-416.

6. Satta G, McHugh TD, Mountford J, Abubakar I, Lipman M. Managing pulmonary nontuberculous mycobacterial infection: Time for a patientcentered approach. Ann Am Thorac Soc. 2014;11:117-21.

7. Casanova JL, Blanche S, Emile JF, Jouanguy E, Lamhamedi S, Altare F, et al. Idiopathic disseminated bacillus Calmette-Guérin infection: a French national retrospective study. Pediatrics. 1996;98(4 Pt 1):774-8.

8. Prando C, Samarina A, Bustamante J, Boisson-Dupuis S, Cobat A, Picard C, et al. Inherited IL-12p40 deficiency: genetic, immunologic, and clinical features of 49 patients from 30 kindreds. Medicine (Baltimore). 2013;92:109-22.

9. Picard C, Fieschi C, Altare F, Al-Jumaah S, Al-Hajjar S, Feinberg J, et al. Inherited interleukin-12 deficiency: IL12B genotype and clinical phenotype of 13 patients from six kindreds. Am J Hum Genet. 2002;70:336-48.

10. Fieschi C, Dupuis S, Catherinot E, Feinberg J, Bustamante J, Breiman A, et al. Low penetrance, broad resistance, and favorable outcome of interleukin 12 receptor beta1 deficiency: medical and immunological implications. J Exp Med. 2003;197:527-35.

11. Newport MJ, Huxley CM, Huston S, Hawrylowicz CM, Oostra BA, Williamson R, et al. A mutation in the interferon-gamma-receptor gene and susceptibility to mycobacterial infection. N Engl J Med. 1996:335:1941-9.

12. Jouanguy $E$, Dupuis $S$, Pallier $A$, Döffinger $R$, Fondanèche $M C$, Fieschi $C$, et al. In a novel form of IFN-gamma receptor 1 deficiency, cell surface receptors fail to bind IFN-gamma. J Clin Invest. 2000;105:1429-36.

13. Holland SM, Dorman SE, Kwon A, Pitha-Rowe IF, Frucht DM, Gerstberger SM, et al. Abnormal regulation of interferon-gamma, interleukin-12, and tumor necrosis factor-alpha in human interferon-gamma receptor 1 deficiency. J Infect Dis. 1998;178:1095-104.

14. Dorman SE, Holland SM. Mutation in the signal-transducing chain of the interferon-gamma receptor and susceptibility to mycobacterial infection. J Clin Invest. 1998;101:2364-9.

15. Dupuis S, Dargemont C, Fieschi C, Thomassin N, Rosenzweig S, Harris J, et al. Impairment of mycobacterial but not viral immunity by a germline human STAT1 mutation. Science. 2001;293:300-3.

16. Chapgier A, Kong X-F, Boisson-Dupuis S, Jouanguy E, Averbuch D, Feinberg J, et al. A partial form of recessive STAT1 deficiency in humans. J Clin Invest. 2009;119:1502-14.

17. Sampaio EP, Bax HI, Hsu AP, Kristosturyan E, Pechacek J, Chandrasekaran P et al. A novel STAT1 mutation associated with disseminated mycobacterial disease. J Clin Immunol. 2012;32:681-9.

18. Averbuch D, Chapgier A, Boisson-Dupuis S, Casanova J-L, Engelhard D. The clinical spectrum of patients with deficiency of Signal Transducer and Activator of Transcription-1. Pediatr Infect Dis J. 2011;30:352-5.

19. Chapgier A, Boisson-Dupuis S, Jouanguy E, Vogt G, Feinberg J, ProchnickaChalufour A, et al. Novel STAT1 alleles in otherwise healthy patients with mycobacterial disease. PLoS Genet. 2006;2, e131.

20. Kreins AY, Ciancanelli MJ, Okada S, Kong X-F, Ramírez-Alejo N, Kilic SS, et al. Human TYK2 deficiency: Mycobacterial and viral infections without hyperIgE syndrome. J Exp Med. 2015;212:1641-62.

21. Hambleton S, Salem S, Bustamante J, Bigley V, Boisson-Dupuis S, Azevedo J, et al. IRF8 mutations and human dendritic-cell immunodeficiency. N Engl J Med. 2011;365:127-38.

22. Bogunovic $D$, Byun $M$, Durfee $L A$, Abhyankar $A$, Sanal O, Mansouri $D$, et al. Mycobacterial disease and impaired IFN- $\gamma$ immunity in humans with inherited ISG15 deficiency. Science. 2012;337:1684-8.

23. Takeda K, Kawai T, Nakazawa Y, Komuro H, Shoji K, Morita K, et al. Augmentation of antitubercular therapy with IFNy in a patient with dominant partial IFNY receptor 1 deficiency. Clin Immunol. 2014;151:25-8.

24. Hallstrand TS, Ochs HD, Zhu Q, Liles WC. Inhaled IFN-gamma for persistent nontuberculous mycobacterial pulmonary disease due to functional IFNgamma deficiency. Eur Respir J. 2004;24:367-70.

25. Bax HI, Freeman AF, Ding L, Hsu AP, Marciano B, Kristosturyan E, et al. Interferon alpha treatment of patients with impaired interferon gamma signaling. J Clin Immunol. 2013;33:991-1001.

26. Ward CM, Jyonouchi H, Kotenko SV, Smirnov SV, Patel R, Aguila H, et al. Adjunctive treatment of disseminated Mycobacterium avium complex infection with interferon alpha-2b in a patient with complete interferongamma receptor R1 deficiency. Eur J Pediatr. 2007;166:981-5.

27. Okada S, Markle JG, Deenick EK, Mele F, Averbuch D, Lagos M, et al. Impairment of immunity to Candida and Mycobacterium in humans with bi-allelic RORC mutations. Science (80-). 2015;349:606-13.
28. Nedorost ST, Elewski B, Tomford JW, Camisa C. Rosacea-like lesions due to familial Mycobacterium avium-intracellulare infection. Int J Dermatol. 1991;30:491-7.

29. Filipe-Santos O, Bustamante J, Haverkamp MH, Vinolo E, Ku C-L, Puel A, et al. $X$-linked susceptibility to mycobacteria is caused by mutations in NEMO impairing CD40-dependent IL-12 production. J Exp Med. 2006;203:1745-59.

30. Deffert C, Cachat J, Krause K-H. Phagocyte NADPH oxidase, chronic granulomatous disease and mycobacterial infections. Cell Microbiol. 2014;16:1168-78.

31. Bustamante J, Arias AA, Vogt G, Picard C, Galicia LB, Prando C, et al. Germline CYBB mutations that selectively affect macrophages in kindreds with X-linked predisposition to tuberculous mycobacterial disease. Nat Immunol. 2011;12:213-21.

32. Nibbering PH, Pos $\mathrm{O}$, Stevenhagen $\mathrm{A}$, Van Furth R. Interleukin-8 enhances nonoxidative intracellular killing of Mycobacterium fortuitum by human granulocytes. Infect Immun. 1993;61:3111-6.

33. Newman GW, Guarnaccia JR, Remold HG, Kazanjian PH. Cytokines enhance neutrophils from human immunodeficiency virus-negative donors and AIDS patients to inhibit the growth of Mycobacterium avium in vitro. J Infect Dis. 1997;175:891-900

34. Hartmann P, Becker R, Franzen C, Schell-Frederick E, Römer J, Jacobs M, et al. Phagocytosis and killing of Mycobacterium avium complex by human neutrophils. J Leukoc Biol. 2001;69:397-404.

35. Appelberg R, Castro AG, Gomes S, Pedrosa J, Silva MT. Susceptibility of beige mice to Mycobacterium avium: role of neutrophils. Infect Immun. 1995;63:3381-7.

36. Bermudez $L E$, Petrofsky M, Stevens P. Treatment with recombinant granulocyte colony-stimulating factor (Filgrastin) stimulates neutrophils and tissue macrophages and induces an effective non-specific response against Mycobacterium avium in mice. Immunology. 1998;94:297-303.

37. Petrofsky M, Bermudez LE. Neutrophils from Mycobacterium avium-infected mice produce TNF-alpha, IL-12, and IL-1 beta and have a putative role in early host response. Clin Immunol. 1999;91:354-8.

38. Hsu AP, Sampaio EP, Khan J, Calvo KR, Lemieux JE, Patel SY, et al. Mutations in GATA2 are associated with the autosomal dominant and sporadic monocytopenia and mycobacterial infection (MonoMAC) syndrome. Blood. 2011;118:2653-5.

39. Dickinson RE, Milne $P$, Jardine L, Zandi S, Swierczek SI, McGovern N, et al. The evolution of cellular deficiency in GATA2 mutation. Blood. 2014; 123:863-74.

40. Spinner MA, Sanchez LA, Hsu AP, Shaw PA, Zerbe CS, Calvo KR, et al. GATA2 deficiency: a protean disorder of hematopoiesis, lymphatics, and immunity. Blood. 2014;123:809-21.

41. Collin M, Dickinson R, Bigley V. Haematopoietic and immune defects associated with GATA2 mutation. Br J Haematol. 2015;169:173-87.

42. Marciano BE, Huang C-Y, Joshi G, Rezaei N, Carvalho BC, Allwood Z, et al. $B C G$ vaccination in patients with severe combined immunodeficiency: complications, risks, and vaccination policies. J Allergy Clin Immunol. 2014:133:1134-41.

43. Ahmad DS, Esmadi M, Steinmann WC. Idiopathic CD4 Lymphocytopenia: Spectrum of opportunistic infections, malignancies, and autoimmune diseases. Avicenna J Med. 2013;3:37-47.

44. Oksenhendler E, Gérard L, Fieschi C, Malphettes M, Mouillot G, Jaussaud R, et al. Infections in 252 patients with common variable immunodeficiency. Clin Infect Dis. 2008:46:1547-54.

45. Winkelstein JA, Marino MC, Lederman HM, Jones SM, Sullivan K, Burks AW, et al. X-linked agammaglobulinemia: report on a United States registry of 201 patients. Medicine (Baltimore). 2006;85:193-202.

46. Höflich C, Sabat R, Rosseau S, Temmesfeld B, Slevogt H, Döcke W-D, et al. Naturally occurring anti-IFN-gamma autoantibody and severe infections with Mycobacterium cheloneae and Burkholderia cocovenenans. Blood. 2004;103:673-5.

47. Döffinger R, Helbert MR, Barcenas-Morales G, Yang K, Dupuis $S$, Ceron-Gutierrez $L$, et al. Autoantibodies to interferon-gamma in a patient with selective susceptibility to mycobacterial infection and organ-specific autoimmunity. Clin Infect Dis. 2004;38:e10-4.

48. Browne SK. Anticytokine autoantibody-associated immunodeficiency. Annu Rev Immunol. 2014;32:635-57.

49. Otome O, O'Reilly M, Lim L. Disseminated Mycobacterium haemophilum skeletal disease in a patient with interferon-gamma deficiency. Intern Med J. 2015;45:1073-6. 
50. Browne SK, Burbelo PD, Chetchotisakd P, Suputtamongkol Y, Kiertiburanakul S, Shaw PA, et al. Adult-onset immunodeficiency in Thailand and Taiwan. N Engl J Med. 2012;367:725-34.

51. Czaja CA, Merkel PA, Chan ED, Lenz LL, Wolf ML, Alam R, et al. Rituximab as successful adjunct treatment in a patient with disseminated nontuberculous mycobacterial infection due to acquired anti-interferon- $\gamma$ autoantibody. Clin Infect Dis. 2014;58:e115-8.

52. Browne SK, Zaman R, Sampaio EP, Jutivorakool K, Rosen LB, Ding L, et al. Anti-CD20 (rituximab) therapy for anti-IFN- $\gamma$ autoantibody-associated nontuberculous mycobacterial infection. Blood. 2012;119:3933-9.

53. Meager A, Vincent A, Newsom-Davis J, Willcox N. Spontaneous neutralising antibodies to interferon-alpha and interleukin-12 in thymoma-associated autoimmune disease. Lancet (London, England). 1997;350:1596-7.

54. Moulias R, Proust J, Wang A, Congy F, Marescot MR, Deville Chabrolle A, et al. Age-related increase in autoantibodies. Lancet (London, England). 1984;1: 1128-9

55. Kartalija M, Ovrutsky AR, Bryan CL, Pott GB, Fantuzzi G, Thomas J, et al. Patients with nontuberculous mycobacterial lung disease exhibit unique body and immune phenotypes. Am J Respir Crit Care Med. 2013;187:197-205.

56. Greinert U, Schlaak M, Rũsch-Gerdes S, Flad H-D, Ernst M. Low In Vitro Production of Interferon- $\gamma$ and Tumor Necrosis Factor-a in HIV-Seronegative Patients with Pulmonary Disease Caused by Nontuberculous Mycobacteria. J Clin Immunol. 2000;20:445-52

57. Kwon YS, Kim EJ, Lee S-H, Suh GY, Chung MP, Kim H, et al. Decreased cytokine production in patients with nontuberculous mycobacterial lung disease. Lung. 2007;185:337-41

58. Milanés-Virelles MT, García-García I, Santos-Herrera Y, Valdés-Quintana M, Valenzuela-Silva CM, Jiménez-Madrigal G, et al. Adjuvant interferon gamma in patients with pulmonary atypical Mycobacteriosis: a randomized, doubleblind, placebo-controlled study. BMC Infect Dis. 2008:8:17.

59. Kim RD, Greenberg DE, Ehrmantraut ME, Guide SV, Ding L, Shea Y, et al. Pulmonary nontuberculous mycobacterial disease: prospective study of a distinct preexisting syndrome. Am J Respir Crit Care Med. 2008;178:1066-74.

60. Lim A, Allison C, Price P, Waterer G. Susceptibility to pulmonary disease due to Mycobacterium avium-intracellulare complex may reflect low IL-17 and high IL-10 responses rather than Th1 deficiency. Clin Immunol. 2010;137:296-302

61. Lim A, Allison C, Tan DBA, Oliver B, Price P, Waterer G. Immunological markers of lung disease due to non-tuberculous mycobacteria. Dis Markers. 2010;29:103-9.

62. Szymanski EP, Leung JM, Fowler CJ, Haney C, Hsu AP, Chen F, et al. Pulmonary Nontuberculous Mycobacterial Infection. A Multisystem, Multigenic Disease. Am J Respir Crit Care Med. 2015;192:618-28.

63. Koh W-J, Kwon OJ, Kim EJ, Lee KS, Ki C-S, Kim JW. NRAMP1 gene polymorphism and susceptibility to nontuberculous mycobacterial lung diseases. Chest. 2005;128:94-101.

64. Horsburgh CR. Mycobacterium avium complex infection in the acquired immunodeficiency syndrome. N Engl J Med. 1991;324:1332-8.

65. Bloch KC, Zwerling L, Pletcher MJ, Hahn JA, Gerberding JL, Ostroff SM, et al. Incidence and clinical implications of isolation of Mycobacterium kansasii: results of a 5-year, population-based study. Ann Intern Med. 1998;129:698-704

66. Campo RE, Campo CE. Mycobacterium kansasii disease in patients infected with human immunodeficiency virus. Clin Infect Dis. 1997;24:1233-8.

67. Meije Y, Piersimoni C, Torre-Cisneros J, Dilektasli AG, Aguado JM. Mycobacterial infections in solid organ transplant recipients. Clin Microbiol Infect. 2014;20 Suppl 7:89-101.

68. Piersimoni C. Nontuberculous mycobacteria infection in solid organ transplant recipients. Eur J Clin Microbiol Infect Dis. 2012;31:397-403.

69. Wu U-I, Holland SM. Host susceptibility to non-tuberculous mycobacterial infections. Lancet Infect Dis. 2015;15.

70. Ho TA, Rommelaere M, Coche E, Yombi J-C, Kanaan N. Nontuberculous mycobacterial pulmonary infection in renal transplant recipients. Transpl Infect Dis. 2010;12:138-42.

71. Al-Anazi KA, Al-Jasser AM, Al-Anazi WK. Infections caused by nontuberculous mycobacteria in recipients of hematopoietic stem cell transplantation. Front Oncol. 2014;4:311.

72. Gaviria JM, Garcia PJ, Garrido SM, Corey L, Boeckh M. Nontuberculous mycobacterial infections in hematopoietic stem cell transplant recipients: characteristics of respiratory and catheter-related infections. Biol Blood Marrow Transplant. 2000;6:361-9.
73. Koetz K, Bryl E, Spickschen K, O'Fallon WM, Goronzy JJ, Weyand CM. T cell homeostasis in patients with rheumatoid arthritis. Proc Natl Acad Sci. 2000;97:9203-8

74. Hodgson K, Morris J, Bridson T, Govan B, Rush C, Ketheesan N. Immunological mechanisms contributing to the double burden of diabetes and intracellular bacterial infections. Immunology. 2015;144:171-85.

75. Winthrop KL, Baxter R, Liu L, Varley CD, Curtis JR, Baddley JW, et al. Mycobacterial diseases and antitumour necrosis factor therapy in USA. Ann Rheum Dis. 2013;72:37-42.

76. Winthrop KL, Chang E, Yamashita S, lademarco MF, LoBue PA. Nontuberculous Mycobacteria Infections and Anti-Tumor Necrosis Factor-a Therapy. Emerg Infect Dis. 2009;15:1556-61.

77. Andrejak C, Nielsen R, Thomsen VO, Duhaut P, Sorensen HT, Thomsen RW Chronic respiratory disease, inhaled corticosteroids and risk of nontuberculous mycobacteriosis. Thorax. 2012;68:256-62.

78. Brode SK, Jamieson FB, Ng R, Campitelli MA, Kwong JC, Paterson JM, Li P, et al. Increased risk of mycobacterial infections associated with anti-rheumatic medications. Thorax. 2015;70:677-82.

79. Hojo M, likura M, Hirano S, Sugiyama H, Kobayashi N, Kudo K. Increased risk of nontuberculous mycobacterial infection in asthmatic patients using longterm inhaled corticosteroid therapy. Respirology. 2012;17:185-90.

80. Mirsaeidi M, Hadid W, Ericsoussi B, Rodgers D, Sadikot RT. Non-tuberculous mycobacterial disease is common in patients with non-cystic fibrosis bronchiectasis. Int J Infect Dis. 2013;17:e1000-4.

81. Chu H, Zhao L, Xiao H, Zhang Z, Zhang J, Gui T, et al. Prevalence of nontuberculous mycobacteria in patients with bronchiectasis: a metaanalysis. Arch Med Sci. 2014;10:661-8.

82. Cole PJ. Inflammation: a two-edged sword-the model of bronchiectasis. Eur J Respir Dis Suppl. 1986;147:6-15.

83. Ojo O, Lagan AL, Rajendran V, Spanjer A, Chen L, Sohal SS, et al. Pathological changes in the COPD lung mesenchyme - Novel lessons learned from in??vitro and in??vivo studies. Pulm Pharmacol Ther. 2014;29(April):1-8.

84. Hoefsloot W, van Ingen J, Magis-Escurra C, Reijers MH, van Soolingen D, Dekhuijzen RPN, et al. Prevalence of nontuberculous mycobacteria in COPD patients with exacerbations. J Infect. 2013;66:542-5.

85. Yeh J-J, Wang Y-C, Sung F-C, Chou CY-T, Kao C-H. Nontuberculosis Mycobacterium Disease is a Risk Factor for Chronic Obstructive Pulmonary Disease: A Nationwide Cohort Study. Lung. 2014;192:403-11.

86. McDonnell MJ, Ward C, Lordan JL, Rutherford RM. Non-cystic fibrosis bronchiectasis. QJM. 2013:106:709-15.

87. Hassett DJ, Borchers MT, Panos RJ. Chronic obstructive pulmonary disease (COPD): Evaluation from clinical, immunological and bacterial pathogenesis perspectives. J Microbiol. 2014;52:211-26.

88. Tang AC, Turvey SE, Alves MP, Regamey N, Tümmler B, Hartl D. Current concepts: host-pathogen interactions in cystic fibrosis airways disease. Eur Respir Rev. 2014;23:320-32.

89. Martiniano SL, Nick JA. Nontuberculous mycobacterial infections in cystic fibrosis. Clin Chest Med. 2015:36:101-15.

90. Bryant JM, Grogono DM, Greaves D, Foweraker J, Roddick I, Inns T, et al. Whole-genome sequencing to identify transmission of Mycobacterium abscessus between patients with cystic fibrosis: a retrospective cohort study. Lancet (London, England). 2013;381:1551-60.

91. Ziedalski TM. Prospective Analysis of Cystic Fibrosis Transmembrane Regulator Mutations in Adults With Bronchiectasis or Pulmonary Nontuberculous Mycobacterial Infection. CHEST J. 2006:130:995.

92. Fowler CJ, Olivier KN, Leung JM, Smith CC, Huth AG, Root H, et al. Abnormal nasal nitric oxide production, ciliary beat frequency, and Toll-like receptor response in pulmonary nontuberculous mycobacterial disease epithelium. Am J Respir Crit Care Med. 2013;187:1374-81.

93. Jang M-A, Kim S-Y, Jeong B-H, Park HY, Jeon K, Kim J-W, et al. Association of CFTR gene variants with nontuberculous mycobacterial lung disease in a Korean population with a low prevalence of cystic fibrosis. J Hum Genet. 2013;58:298-303.

94. Prevots DR, Marras TK. Epidemiology of human pulmonary infection with nontuberculous mycobacteria: a review. Clin Chest Med. 2015;36:13-34.

95. Andréjak C, Thomsen VØ, Johansen IS, Riis A, Benfield TL, Duhaut $P$, et al. Nontuberculous pulmonary mycobacteriosis in Denmark: incidence and prognostic factors. Am J Respir Crit Care Med. 2010;181:514-21.

96. Ye $\mathrm{P}$, Kirschner DE. Measuring emigration of human thymocytes by T-cell receptor excision circles. Crit Rev Immunol. 2002;22:483-97. 
97. Cicin-Sain L, Messaoudi I, Park B, Currier N, Planer S, Fischer M, et al. Dramatic increase in naive $T$ cell turnover is linked to loss of naive $T$ cells from old primates. Proc Natl Acad Sci U S A. 2007;104:19960-5.

98. Naylor K, Li G, Vallejo AN, Lee W-W, Koetz K, Bryl E, Witkowski J, et al. The influence of age on T cell generation and TCR diversity. J Immunol. 2005; 174:7446-52

99. Nikolich-Zugich J. Ageing and life-long maintenance of T-cell subsets in the face of latent persistent infections. Nat Rev Immunol. 2008;8:512-22.

100. Griffith DE, Girard WM, Wallace RJ. Clinical features of pulmonary disease caused by rapidly growing mycobacteria. An analysis of 154 patients. Am Rev Respir Dis. 1993;147:1271-8.

101. Tsuyuguchi K, Suzuki K, Matsumoto H, Tanaka E, Amitani R, Kuze F. Effect of oestrogen on Mycobacterium avium complex pulmonary infection in mice. Clin Exp Immunol. 2001;123:428-34.

102. Danley J, Kwait R, Peterson DD, Sendecki J, Vaughn B, Nakisbendi K, et al. Normal estrogen, but low dehydroepiandrosterone levels, in women with pulmonary Mycobacterium avium complex. A preliminary study. Ann Am Thorac Soc. 2014;11:908-14.

103. Mirsaeidi M, Sadikot RT. Gender susceptibility to mycobacterial infections in patients with non-CF bronchiectasis. Int J Mycobacteriology. 2015:4:92-6

104. Chan ED, Iseman MD. Slender, older women appear to be more susceptible to nontuberculous mycobacterial lung disease. Gend Med. 2010;7:5-18

105. Dirac MA, Horan KL, Doody DR, Meschke JS, Park DR, Jackson LA, et al. Environment or host?: A case-control study of risk factors for Mycobacterium avium complex lung disease. Am J Respir Crit Care Med. 2012;186:684-91.

106. Lee SJ, Ryu YJ, Lee JH, Chang JH, Shim SS. The impact of low subcutaneous fat in patients with nontuberculous mycobacterial lung disease. Lung. 2014;192:395-401.

107. Ordway D, Henao-Tamayo M, Smith E, Shanley C, Harton M, Troudt J, et al. Animal model of Mycobacterium abscessus lung infection. J Leukoc Biol. 2008;83:1502-11.

108. Leung JM, Fowler C, Smith C, Adjemian J, Frein C, Claypool RJ, et al. A familial syndrome of pulmonary nontuberculous mycobacteria infections. Am J Respir Crit Care Med. 2013:188:1373-6.

109. Iseman MD, Buschman DL, Ackerson LM. Pectus excavatum and scoliosis. Thoracic anomalies associated with pulmonary disease caused by Mycobacterium avium complex. Am Rev Respir Dis. 1991;144:914-6.

110. Jeon K, Kim S-Y, Jeong B-H, Chang B, Shin SJ, Koh W-J. Severe vitamin D deficiency is associated with non-tuberculous mycobacterial lung disease: a case-control study. Respirology. 2013;18:983-8.

111. Chun RF, Adams JS, Hewison M. Immunomodulation by vitamin D: implications for TB. Expert Rev Clin Pharmacol. 2011:4:583-91.

112. Casanova J-L, Abel $L$. The human model: a genetic dissection of immunity to infection in natural conditions. Nat Rev Immunol. 2004;4:55-66.

113. Tsai T-F, Chiu H-Y, Song M, Chan D. A case of latent tuberculosis reactivation in a patient treated with ustekinumab without concomitant isoniazid chemoprophylaxis in the PEARL trial. $\mathrm{Br} J$ Dermatol. 2013;168:444-6.

114. Souto A, Maneiro JR, Salgado E, Carmona L, Gomez-Reino JJ. Risk of tuberculosis in patients with chronic immune-mediated inflammatory diseases treated with biologics and tofacitinib: a systematic review and meta-analysis of randomized controlled trials and long-term extension studies. Rheumatology (Oxford). 2014;53:1872-85.

115. Hopman RK, Lawrence SJ, Oh ST. Disseminated tuberculosis associated with ruxolitinib. Leukemia. 2014;28:1750-1.

116. Winthrop KL, Iseman M. Bedfellows: mycobacteria and rheumatoid arthritis in the era of biologic therapy. Nat Rev Rheumatol. 2013;9:524-31.

117. Novosad SA, Winthrop KL. Beyond tumor necrosis factor inhibition: the expanding pipeline of biologic therapies for inflammatory diseases and their associated infectious sequelae. Clin Infect Dis. 2014;58:1587-98.

118. de Masson A, Maillart E, Veziris N, Meyssonnier V, Papeix C, Caumes E. Cavitary pulmonary disease in a patient treated with natalizumab. Presse Med. 2014:43:1009-12.

119. Chan ED, Kaminska AM, Gill W, Chmura K, Feldman NE, Bai X, et al. Alpha-1antitrypsin (AAT) anomalies are associated with lung disease due to rapidly growing mycobacteria and AAT inhibits Mycobacterium abscessus infection of macrophages. Scand J Infect Dis. 2007;39:690-6.

120. McGrath EE, Bardsley P. An association between Mycobacterium malmoense and coal workers' pneumoconiosis. Lung. 2009;187:51-4.

121. Kim YM, Kim M, Kim SK, Park K, Jin S-H, Lee US, et al. Mycobacterial infections in coal workers' pneumoconiosis patients in South Korea. Scand J Infect Dis. 2009;41:656-62

122. Witty LA, Tapson VF, Piantadosi CA. Isolation of mycobacteria in patients with pulmonary alveolar proteinosis. Medicine (Baltimore). 1994;73:103-9.

\section{Submit your next manuscript to BioMed Central and we will help you at every step:}

- We accept pre-submission inquiries

- Our selector tool helps you to find the most relevant journal

- We provide round the clock customer support

- Convenient online submission

- Thorough peer review

- Inclusion in PubMed and all major indexing services

- Maximum visibility for your research

Submit your manuscript at www.biomedcentral.com/submit
) Biomed Central 